\title{
Smoking cessation after an acute coronary syndrome
}

\author{
Abstract \\ One of the most important secondary prevention strategies, after an acute coronary \\ syndrome in smoking patients, is smoking cessation. To achieve this goal, in hospital \\ counseling, pharmacological treatment and referral to a cardiac rehabilitation program are \\ the three more relevant measures. The cessation effort must be extended post-discharge by \\ referral to a smoking cessation program.
}

Keywords: smoking cessation, acute coronary syndrome, secondary prevention
Volume 5 Issue I - 2018

\section{Mauricio Fernandez}

Clinica Alemana de Santiago, Universidad del Desarrollo, Chile

Correspondence: Mauricio Fernandez, Clinica Alemana de Santiago, Universidad del Desarrollo, A Las Condes, Santiago, Chile, Tel 569 98851829, Email mfernandezr@alemana.cl

Received: December 08, 2017 | Published: January 19, 2018

\section{Introduction}

Diseases related to tobacco consumption are one of the main causes of hospital admissions, of these, cardiovascular diseases are among the most important. After a cardiovascular event such as an acute myocardial infarction with or without ST elevation, unstable angina or coronary revascularization procedure, a series of secondary prevention measures should be considered. Within these, complete smoking cessation is proposed as a primary goal.

All acute coronary syndrome management guidelines (with and without ST elevation) recommend assessing the use of tobacco, strongly recommending that the patient and family members stop smoking and avoid secondhand smoke. Proper treatment considers counseling, pharmacological therapy and entering a tobacco cessation program. ${ }^{1-3}$

\section{Discussion}

The hospitalization of a smoker patient constitutes a great opportunity to apply measures of smoking cessation. It is a moment when patients rethink about their lifestyles and are open to changes towards healthier habits. At this time behavioral treatments involving exercise, healthy food, and smoking cessation are associated with both a short and long-time benefit. Smoking cessation reduces substantially the occurrence of new cardiovascular events and mortality at six months, ${ }^{4,5}$ and accounts of an approximate $30 \%$ lower risk rate of death and myocardial infarction during the subsequent 3 to 7 years. ${ }^{6}$

In fact, various studies in patients after an acute coronary syndrome, showed that smoking cessation reduces future mortality up to approximately $50 \%$, constituting one of the most powerful secondary prevention measures. ${ }^{7.8}$ Among the most important strategies to follow in this group of patients are, counseling during hospitalization, admission to a cardiac rehabilitation program and the use of pharmacological therapy.

Regarding counseling, this should be implemented from the moment the patient is hospitalized, asking about the consumption of tobacco, advising about quitting and the benefits that this entails.
The more professionals involved in giving advice (doctors, nurses, kinesiologists, assistants, others), the more effective. Also, the intensity level of counseling leads to better results. In a review by Rigotti and cols. in Cocharane, a total hospital intervention of more than 15 minutes, associated with an after-discharge follow-up beyond the first month, was the most efficient counseling strategy. ${ }^{9}$

The use of nicotinic replacement therapy, bupropion and varenicline are the current validated pharmacological treatments for smoking cessation. Although these three drugs are accepted as therapeutic alternatives, in the patient hospitalized after an acute myocardial infarction, the effectiveness of bupropion is not clear and there are no randomized controlled studies with nicotinic replacement therapy.$^{10}$ Regarding nicotine replacement therapy, although there are no randomized controlled studies, its use has proven to be safe, and it is recommended once the patient is stabilized (stable hemodynamics and absence of serious arrhythmias). It can be used in patches, gums or mouth spray. ${ }^{8,9,11}$

A recently study ${ }^{12}$ evaluated the use of varenicline in smokers hospitalized for acute coronary syndrome. The study showed a significantly higher rate of smoking cessation at 6 months post infarction in the group with varenicline in relation to placebo $(47 \%$ vs $32 \%$ ). The use of varenicline in this setting proved to be safe, showing no significant differences in cardiovascular complications.

\section{Conclusion}

It is important to point out that achieving cessation of tobacco consumption after an acute coronary syndrome, as already mentioned, is perhaps the most effective measure in terms of preventing a new future event. In order to achieve this goal, all different therapeutic approaches, pharmacological and non-pharmacological, must be considered. These measures should be initiated during the hospitalization phase by the treating team, and controlled after discharge. All patients must receive anti-smoking counseling and enter a cardiac rehabilitation program. Pharmacological therapy should be considered in all cases. Patients with a high level of addiction must be a referred to a tobacco cessation program. 


\section{Acknowledgements}

None.

\section{Conflicts of interest}

The author declare that there is no conflict of interest.

\section{References}

1. Amsterdam EA, Wenger NK, Brindis RG, et al. AHA/ACC guideline for the management of patients with non-ST-elevation acute coronary syndromes: a report of the American College of Cardiology/American Heart Association Task Force on Practice Guidelines. J Am Coll Cardiol. 2014;64(24):e139-e228.

2. Roffi M, Patrono C, Collet JP, et al. 2015 ESC guidelines for the management of acute coronary syndromes in patients presenting without persistent ST-segment elevation: Task Force for the Management of Acute Coronary Syndromes in Patients Presenting without Persistent STSegment Elevation of the European Society of Cardiology (ESC). Eur Heart J. 2016;37(3):267-315.

3. Ibanez B, James S, Agewall S, et al. ESC Guidelines for the management of acute myocardial infarction in patients presenting with ST-segment elevation. Eur Heart J. 2017;39(2):119-177.

4. Chow CK, Jolly S, Rao-Melacini P, et al. Association of diet, exercise, and smoking modification with risk of early cardiovascular events after acute coronary syndromes. Circulation. 2010;121(6):750-758.
5. Giannuzzi P, Temporelli PL, Marchioli R, et al. Global secondary prevention strategies to limit event recurrence after myocardial infarction: results of the GOSPEL study, a multicenter, randomized controlled trial from the Italian Cardiac Rehabilitation Network. Arch Intern Med. 2008;168(20):2194-2204

6. Critchley J, Capewell S. Smoking cessation for the secondary prevention of coronary heart disease. Cochrane Database Syst Rev. 2004;1:CD003041.

7. Wilson K, Gibson N, Willan A, et al. Effect of smoking cessation on mortality after myocardial infarction: meta-analysis of cohort studies. Arch Intern Med. 2000;160(7):939-944.

8. Thomson CC, Rigotti NA. Hospital and clinic-based smoking cessation interventions for smokers with cardiovascular disease. Prog Cardiovasc Dis. 2003;45(6):459-479.

9. Rigotti NA, Clair C, Munafò MR, et al. Interventions for smoking cessation in hospitalised patients. Cochrane Database of Systematic Reviews. 2012;(5):CD001837.

10. Simon JA, Duncan C, Huggins J, et al. Sustained-release bupropion for hospital-based smoking cessation: a randomized trial. Nicotine Tob Res. 2009;11(6):663-669.

11. Jiménez Ruiz CA, de Granda Orive JI, Solano Reina S, et al. Guidelines for the Treatment of Smoking in Hospitalized Patients. Arch Bronconeumol. 2017;53(7):387-394.

12. Eisenberg MJ, Windle SB, Roy N, et al. EVITA Investigators. Varenicline for Smoking Cessation in Hospitalized Patients with Acute Coronary Syndrome. Circulation. 2016;133(1):21-30. 